and the departments of University College Hospital, Ibadan, who gave their assistance.

The Wellcome Foundation kindly supplied the vaccines and the needleless injectors used in this trial.

Reprints of this paper will be available from Professor R. G. Hendrickse, Department of Paediatrics, U.C.H., Ibadan, Nigeria.

\section{REFERENCES}

Budd, M. A., Scholtens, R. G., McGehee, R. F., jun., and Gardner, P (1965). Presented to the American Public Health Association's 93rd Annual Meeting, Chicago, Illinois.

Collard, P., Hendrickse, R. G., Montefiore, D., Sherman, P., Van Der Wall, H. M., Morley, D., Goffe, A.' P., Lawrence, G. D., and Pollock, T. M. (1961). Brit. med. f., 2, 1246.

Daily Times, 6 July 1966. Lagos, Nigeria.

Du Pan, R. M. (1965). Bull. Wld Hlth Org., 32, 331.

Gans, B., Macnamara, F. N., Morley, D. C., Thomson, S. W., and Watt, A. (1961). W. Afr. med. f., 10, 253.

Hendrickse, R. G., Montefiore, D., Peradze, T., Sherman, P. M., and Powell, M. (1966a). f. trop. med. Hyg., 69, 112.
779.

- - and Sofoluwe, G. O. (1965). Bull. Wld Hith Org., 32, 803.

470 .

- and Sherman, P. M. (1965). Arch. ges. Virusforsch., 16, 27.

Krugman, S. (1965). Arch. ges. Virusforsch., 16, 339.

Meyer, H. M., jun., Hostetler, D. D., jun., Bernheim, B. C., Rogers, N. G., Lambin, P., Chassary, A., Labusquière, R., and Smadel, J. E. (1964). Bull. Wld Hlth Org., 30, 783.

Morley, D. (1964). Proc. roy. Soc. Med., 57, 846.

Woodland, M., and Martin, W. J. (1963). F. Hyg. (Lond.), 61, 115.

New Nigeria, 2 July 1966. Kaduna, Nigeria.

Rey, M., Baylet, R., Cantrelle, P., Dauchy, S., Diop Mar, I., and Guérin, M. (1965a). Bull. Soc. méd. Afr. noire Langue franç., 10, 392.

Diop Mar, I., and Cantrelle, P. (1965b). Arch. ges. Virus forsch., 16, 260.

Smorodintsev, A. A., Boychuk, L. M., Shikina, E. S., Meshalova, V. N., Taros, L. Y., Aminova, M. G., Revenok, N. D., and Safarov, D. I. (1965). Ibid., 16, 284.

W.H.O. (1963). Wld Hlth Org. techn. Rep. Ser., No. 263.

- (1964). Ibid., No. 283.

\title{
Intestinal Hormones and Plasma Insulin: an Insulinotropic Action of Secretin*
}

\author{
D. R. BOYNS, $\dagger \ddagger$ M.B., B.SC., M.R.C.P. ; R. J. JARRETT, $\dagger$ M.A., M.D. ; H. KEEN, $\dagger$ M.B., M.R.C.P.
}

Brit. med. J., 1967, 2, 676-678

McIntyre, Holdsworth, and Turner (1964) and Elrick, Stimmler, Hlad, and Arai (1964) demonstrated the greater effect of oral glucose administration, compared with intravenous, in stimulating a rise in plasma insulin levels. McIntyre, Holdsworth, and Turner (1965) presented evidence that the augmentation of the response was due to the release of a hormone from the gut wall. At present there are two obvious candidates for this role-secretin and glucagon (Lancet, 1966). We have already published evidence that there is no rise in fasting venous plasma immunoreactive insulin levels when endogenous secretin release is stimulated by intraduodenal instillation of acid (Boyns, Jarrett, and Keen, 1966). In this paper we report further studies of the effect of endogenous secretin on the plasma immunoreactive insulin response to intravenous glucose. In addition, the effects of purified porcine secretin have been studied and compared with those of purified cholecystokinin/pancreozymin.

\section{Materials and Methods}

Endogenous secretin was stimulated by intraduodenal infusion of $0.05 \mathrm{~N}$ citric acid ( $p \mathrm{H} 2.5$ ), $5 \mathrm{ml} . /$ minute for alternate minutes over 20 minutes. Purified secretin $(20,000$ clinical units/mg.) and purified cholecystokinin/pancreozymin -referred to subsequently as C.C.K.-(1,500 Ivy dog units/ mg.) were obtained from Professor J. E. Jorpes and Dr. V. Mutt ; $6 \mu \mathrm{g}$. of secretin or $50 \mu \mathrm{g}$. of C.C.K. was made up in $20 \mathrm{ml}$. of physiological saline and injected intravenously at a rate of $1 \mathrm{ml} . /$ minute.

\footnotetext{
* Based on a communication to the Medical and Scientific Section of the British Diabetic Association, 30 September 1966.

† Department of Medicine, Guy's Hospital, London S.E.1.

$\ddagger$ Present address: Arlais, St. Ishmaels Road, Kidwelly, Carms.
}

Intravenous infusions of $5 \%$ glucose were administered at a rate of $20 \mathrm{~g}$. of glucose per hour. Preliminary experiments had shown that this rate of infusion provoked only a small and slow rise in plasma immunoreactive insulin levels. When two infusions were given on the same day, two hours elapsed between the end of the first and the beginning of the second infusion.

Blood samples were taken into heparinized tubes from an indwelling polyethylene cannula placed in an antecubital vein. Then $0.1 \mathrm{ml}$. was transferred to $3 \mathrm{ml}$. of $1 \%$ potassium fluoride for subsequent estimation of blood sugar on an autoanalyser, the method of Hoffman (1937) being used. Plasma was separated by centrifugation and was assayed for insulin by a double antibody precipitation method similar to those described by Morgan and Lazarow (1963) and Hales and Randle (1963).

All the experiments reported were performed in the morning. after an overnight fast, on five healthy men aged $25-40$, who lay at rest during the experimental period. All had normal oral glucose tolerance.

\section{Results}

In three subjects the blood sugar and plasma immunoreactive insulin response to intravenous glucose infusion was measured with an intraduodenal tube in position. In the control infusion, intraduodenal infusion of physiological saline, $5 \mathrm{ml}$. per minute for alternate minutes, was carried out for the first 20 minutes of the glucose infusion. The results were compared with a similar infusion of citric acid (Fig. 1). In none of the three subjects did the infusion of citric acid augment the response of the plasma immunoreactive insulin to intravenous glucose.

Secretin or C.C.K. was infused intravenously, alone (Fig. 2) and along with intravenous glucose (Fig. 3). In neither case 
was any effect of C.C.K. observed on plasma immunoreactive insulin or blood sugar levels. However, secretin given without glucose caused a rise-approximately twofold at its peak-in plasma immunoreactive insulin during the infusion. The immunoreactive insulin levels returned towards baseline values before the infusion was discontinued. When secretin was given together with intravenous glucose, peak levels of plasma immunoreactive insulin were reached during the secretin infusion. Though only a few comparisons have been made, it appears that the effect of combined secretin and glucose is greater than the sum of secretin and glucose given independently.

\section{Discussion}

Since this work was begun an insulinotropic effect of secretin, both crude and purified, has been reported in both man and in the regulation of glucose metabolism. It seems rcasonable to conclude that the demonstrated effects of secretin on insulin release have been with unphysiological amounts of the hormone. Such a conclusion is supported by the experimental evidence of Wang and Grossman (1951). These workers were unable to show a stimulatory effect of glucose in the small intestine upon either secretin or pancreozymin release.

The other candidate for the hypothetical insulinotropic hormone is glucagon, which is also found in extracts of intestinal mucosa (Makman and Sutherland, 1964 ; Samols, Tyler, Megyesi, and Marks, 1966). The structure of glucagon has been known for some time, and the structure of secretin has recently been described (Mutt and Jorpes, 1967). The similarity in structure between the two hormones has already been remarked (Mutt, Magnusson, Jorpes, and Dahl, 1965), and can be easily seen in Fig. 4. This structural similarity may
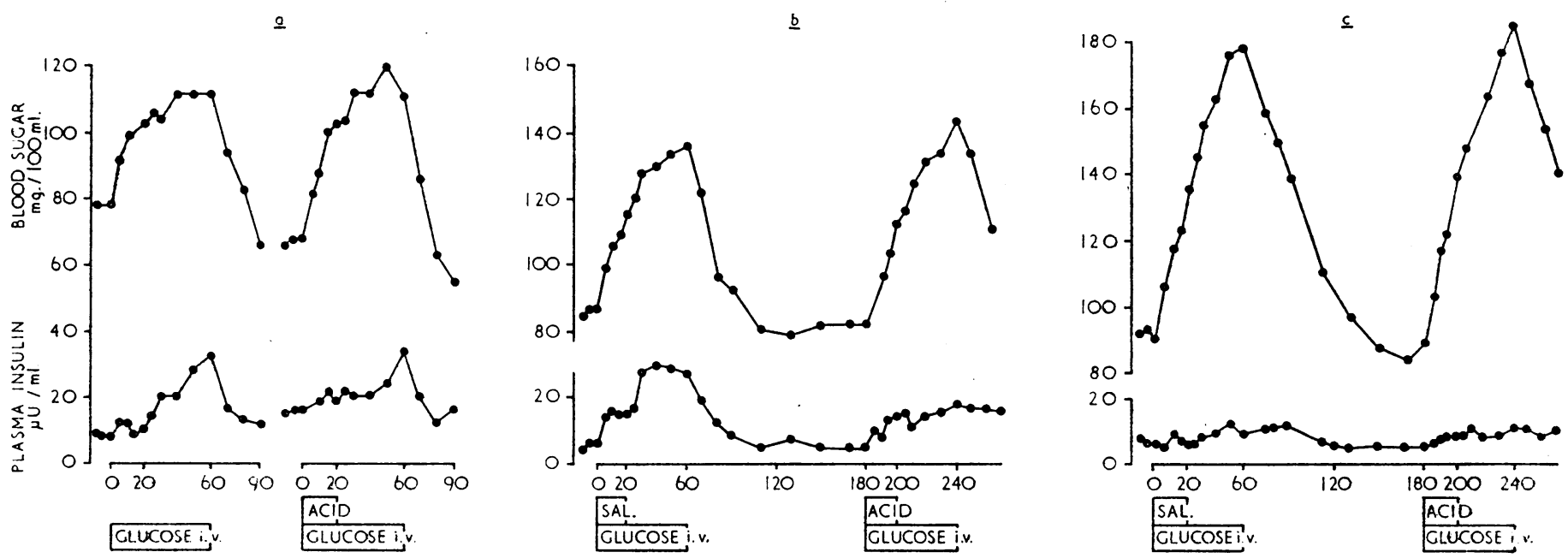

Fig. 1.-Effect of intravenous infusion of $5 \%$ glucose together with intraduodenal saline or citric acid infusions on the blood sugar and plasma immunoreactive insulin in three subjects.

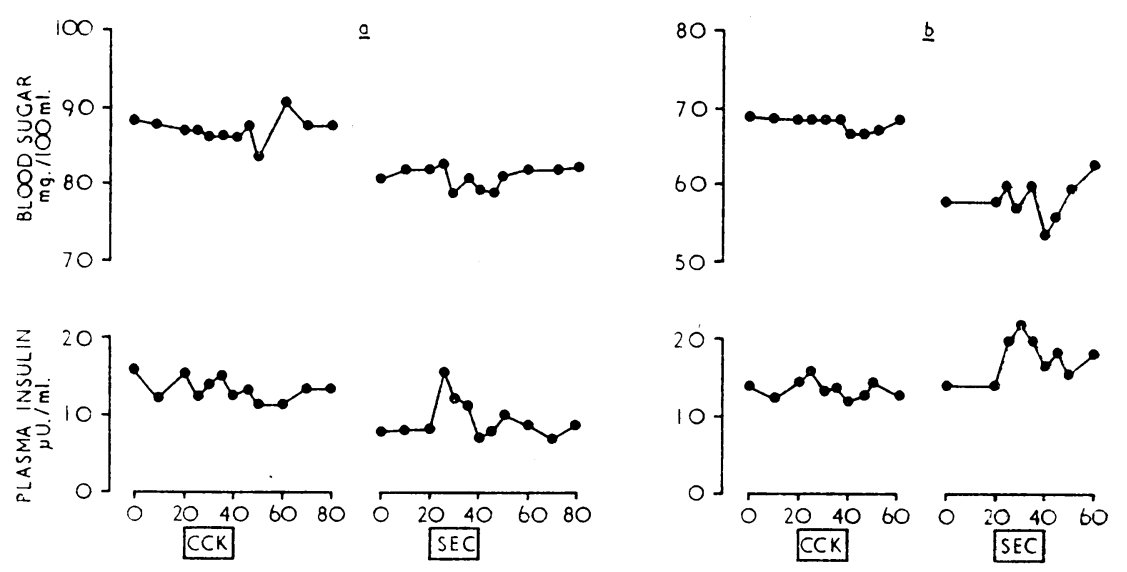

FIG. 2.-Effect of intravenous infusions of purified secretin or cholecystokinin/pancreo-

zymin on the blood sugar and plasma immunoreactive insulin of two fasting subjects.

dog (Unger, Ketterer, Eisentraut, and Dupré, 1966 ; Dupré, Rojas, White, Unger, and Beck, 1966). These reports, together with our own results, confirm the inference of Lechin (1962), who, finding that crude secretin lowered the serum potassium level in normal humans and normal dogs but not in pancreatectomized or alloxan diabetic dogs, postulated an increased secretion of insulin in response to the secretin. They are also consistent with the evidence that purified secretin stimulates the release of insulin from in-vitro preparations of dog and rabbit pancreas (Pfeiffer, Telib, Ammon, Melani, and Ditschuneit, 1965). However, while we are able to confirm the insulinotropic properties of secretin, our failure to influence the plasma insulin levels by infusion of acid into the duodenum throws doubt on the existence of a physiological role of secretin explain the comparable insulinotropic properties of the two hormones, and, further, suggests the possible existence of one or more similar polypeptides with a specific function relating to insulin release. The intestinal mucosa may entertain as interesting a family of polypeptides as the hypothalamus.

\section{Summary}

Intravenous infusions of purified secretin administered to healthy men provoked a rise in the level of the fasting venous plasma immunoreactive insulin and augmented the immunoreactive insulin response to intravenous glucose. Purified cholecystokinin/pancreozymin, similarly infused, had no effect 

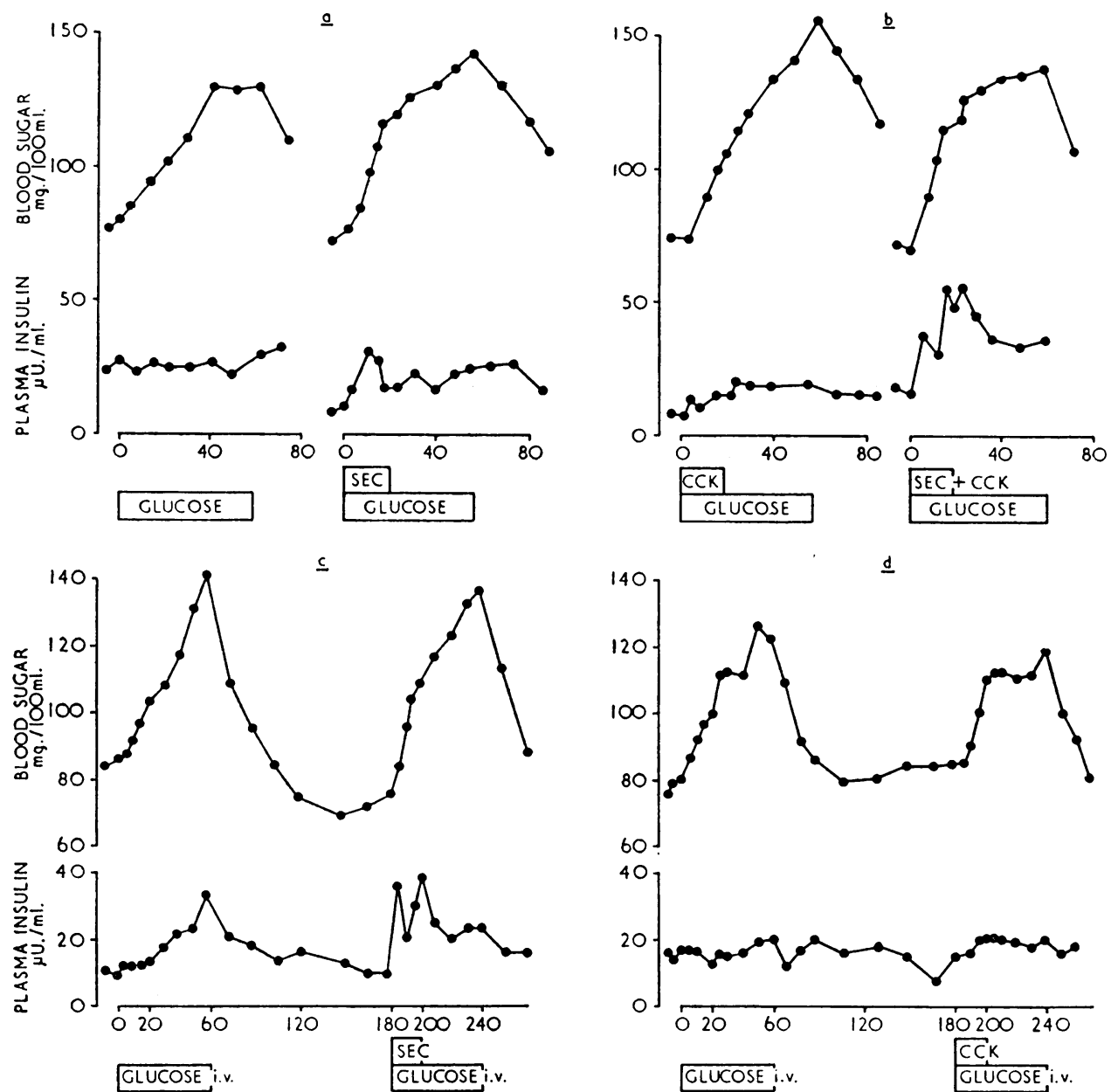

Fig. 3.-Effect of intravenous infusions of $5 \%$ glucose alone and together with secretin or cholecystokinin/pancreozymin on the blood sugar and plasma immunoreactive insulin in four subjects.

on immunoreactive insulin levels. In contrast with the effect of exogenous secretin, endogenous secretin, stimulated by intraduodenal instillation of citric acid, did not augment the plasma

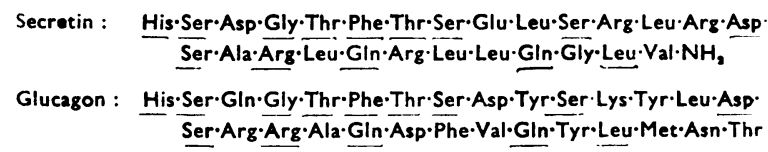

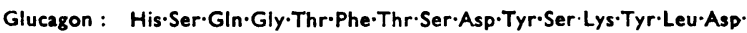

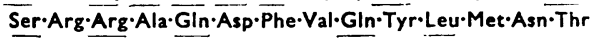

Fio. 4.-Structure of porcine secretin compared with that of glucagon. (By courtesy of Drs. Mutt and Jorpes, 1967.)

Immunoreactive insulin levels achieved during intravenous glucose infusion. It is suggested that secretin, though insulinotropic, is only so in unphysiological amounts.

We are grateful to Drs. Victor Johnson and Geoffrey Machen for their help in these investigations, and to Professor J. E. Jorpes and Dr. V. Mutt for a generous supply of purified hormones and for valuable comment. We would also like to thank Mr. Barry Young, Miss Anthea Jones, and Staff Nurse Elizabeth Longhurst, S.R.N., for technical assistance. Acknowledgement is made to the Wellcome Trust and to the British Diabetic Association for facilitating these studies.
R. J. Jarrett, to whom requests for reprints should be addressed, is in receipt of a grant from the Medical Research Council.

\section{REFERENCBS}

Boyns, D. R., Jarrett, R. J., and Keen, H. (1966). Lancet, 1, 409. Dupré, J., Rojas, L., White, J. J., Unger, R. H., and Beck, J. C. (1966). Ibid., 2, 26.

Elrick, H., Stimmler, L., Hlad, C. J., and Arai, Y. (1964). F. clin. Endocr. 24, 1076

Hales, C. N., and Randle, P. J. (1963). Lancet, 1, 790.

Hoffman, W. S. (1937). \%. biol. Chem., 120, 51.

Lancet, 1966, 2, 35 .

Lechin, C. F. (1962). Acta physiol. lat.-amer., 12, 370.

McIntyre, N., Holdsworth, C. D., and Turner, D. S. (1964). Lancet, $2,20$.

Makman, M. H., and Sutherland, E. W. (1964). Endocrinology, 75, 127 Morgan, C. R., and Lazarow, A. (1963). Diabetes, 12, 115.

Mutt, V., and Jorpes, J. E. (1967). 4th International Symposium on the Chemistry of Natural Products, Stockholm, 1966, Recent Progr. Hormone Res., vol. 23. In press.

Magnusson, S., Jorpes, J. E., and Dahl, E. (1965). Biochemistry, 4, 2358 .

Pfeiffer, E. F., Telib, M., Ammon, J., Melani, F., and Ditschuneit, H. (1965). Diabetologia, 1, 131.

Samols, E., Tyler, J., Megyesi, C., and Marks, V. (1966). Lancet, 2, 727. Unger, R.'H., Ketterer, H., Eisentraut, A., and Dupré, J. (1966). Ibid., 2, 24.

Wang, C. C., and Grossman, M. I. (1951). Amer. F. Physiol., 164, 527. 